\title{
Body Mass Index and Associated Factors of School Absenteeism by School Feeding Program at Selected Primary Schools in Addis Ababa, Ethiopia: A Comparative Study
}

\author{
Solomon Muluken Ayehu $\mathbb{D}^{1}$ and Addisu Tadesse Sahile $\mathbb{i}^{2}$ \\ ${ }^{1}$ Department of Emergency, Menelik II Referral Hospital, Addis Ababa, Ethiopia \\ ${ }^{2}$ Department of Public Health, Unity University, Addis Ababa, Ethiopia \\ Correspondence should be addressed to Addisu Tadesse Sahile; sahdis91@gmail.com
}

Received 3 October 2020; Revised 22 November 2020; Accepted 13 March 2021; Published 24 March 2021

Academic Editor: Abdel Halim Salem

Copyright (C) 2021 Solomon Muluken Ayehu and Addisu Tadesse Sahile. This is an open access article distributed under the Creative Commons Attribution License, which permits unrestricted use, distribution, and reproduction in any medium, provided the original work is properly cited.

Background. Quality of education plays a crucial role in the social, economic, and political development of a nation. Primary school is a vital stage in developing the personality and consciousness of school children. Objective. The study assessed the Body Mass Index and factors associated with School Absenteeism at selected primary schools in Addis Ababa, 2018. Methods. A comparative cross-sectional study was undertaken on 324 (162 each group) from selected primary schools of Addis Ababa from May 02 to July 30, 2018. All participants and their families provided written informed consent and assent. A systematic random sampling technique was used to select participants, where the list of students was once identified from the selected schools. An independent $t$-test was undertaken at $p$ value $<0.05$ as the statistically significant level. And, binary logistics regression was used for the identification of factors statistically associated with school absenteeism, with its respective $95 \%$ confidence interval (CI) and $p$ value of $<0.05$ significant level. Findings. There was a statistically significant difference between feeding and nonfeeding participants on average weight, school absenteeism, and BMI for age, at $p<0.05$. Participants who enrolled in the school feeding program had a higher average weight than nonfeeding participants $(p<0.05)$. Participants from the feeding group had lower average school absenteeism than their counter participants $(p<0.05)$. The average BMI for age was significantly higher among feeding participants than nonfeeding participants $(p<0.05)$. The odds of having school absenteeism were 1.796 times higher among feeding participants than among nonfeeding participants (AOR: 1.796; 95CI:1.061-3.042, $p<0.05$ ). The odds of sustaining absenteeism from the school were 2.257 times higher among feeding participants than among nonfeeding participants (AOR: 2.257; 95\%CI: 1.291-3.948; $p<0.05)$. Conclusion. A higher number of school absenteeism, average weight, and BMI for age were observed in participants enrolled in the school feeding program than those who did not get enrolled in the feeding program. Large-scale studies were recommended to testify the impacts of school feeding on absenteeism.

\section{Introduction}

Quality of education plays a crucial role in the social, economic, and political development of a nation. Although progress was made, with a norm that education for all as part of Millennium Development Goals (MDG), about 58 million school-age children were out of school globally [1]. Assuring children acquiring basic knowledge and skills for their wellbeing could be the key responsibilities of all the governing bodies [2].
Malnutrition preceded by the inappropriate eating practice impacted adolescents' academic performance [3]. Though nutrition has a vital role in the development of humans including the brain throughout life [4], nutritional problems affect the ability of children to learn [5]. A balanced diet is more importantly advocated for productivity, cognitive wellbeing, endurance, and growth physically [6]. In sub-Saharan Africa, 25\% of children sustained impaired mental development following malnutrition [7] and school children were at an increased risk 
of dropout and repetition of grades due to malnutrition [8].

Despite the higher burden of malnutrition among school children [9-12], where stunting affects up to $49 \%$ of children in Ethiopia and where underweight accounted of 59\% [13], the coverage of school feeding program was low.

Although the school feeding program was introduced with the aim of increasing school attendance, enrollment, and retention, the coverage was low [14]. However, the impact of school feeding was not always positive on nutritional status; a corpus of evidence reported the presence of a positive link between school feeding and nutritional status [15-17]. Literature also reported the positive impact of the school feeding program on school attendance. Though school absenteeism was seen as a complex problem with multifactorial origin [18], the presence of a school feeding program reduces school absenteeism [15, 19-21].

To the best of the researcher's knowledge, the role of the school feeding programs on nutritional status and absenteeism was not well investigated in Addis Ababa. Therefore, this study assessed the BMI and school absenteeism within feeding versus nonfeeding groups in the study settings.

\section{Methods}

2.1. Participants and Study Design. The study received ethics approval from Sante Medical College, Research review and Ethics Committee, and was undertaken in selected primary schools of Addis Ababa from May 02 to July 30, 2018. All participants and their families provided written informed consent and assent. An institutional-based cross-sectional study was conducted at selected primary schools in Yeka subcity. The source population was primary school students in Yeka subcity. The study population was students at the selected primary schools. The selected schools were Kokebe Tsebah, Yewotatoch Genet, and Yeka Misrak Chora Primary Schools. A systematic random sampling technique was used to select participants, where the list of students was once identified. The sample size was determined with Epi-Data, based on double population formula presented as $n=(Z \alpha / 2+Z \beta) 2 *(p 1(1-p 1)+p p 2(1-p 2)) /(p 1-p 2)$ 2 , where $Z \alpha / 2$ is the critical value of the Normal distribution at $\alpha / 2$ (for a confidence level of $95 \%, \alpha$ is 0.05 and the critical value is 1.96), $Z \beta$ is the critical value of the normal distribution at $\beta$ (for a power of $80 \%, \beta$ is 0.2 and the critical value is 0.84 ) and $p 1$ and $p 2$ are the expected sample proportions of the two groups. And finally, the sample size became 294, considering the $10 \%$ nonresponse rate; the final result was 324 for the two groups, with 162 for each group. Data were collected with a structured and pretested interviewer-administered questionnaire with an anthropometric measurement. A pretest was undertaken in Ewuket Fana Primary School on 5\% of the sample size. The dependent variables were BMI and school absenteeism.

2.2. Operational Definitions. School absenteeism is any absence from school due to reasons other than the formal school closure days (due to either national holidays or religious days for which the school is closed). Interventional group: students who were included in the school feeding program from selected primary schools. Noninterventional group: students who were not part of the school feeding program but found in selected primary schools. WHZ: a child who had $\mathrm{WHZ}<-2 \mathrm{SD}$ was categorized as low weight-for-height which implies undernutrition, and those who had WHZ > 2SD were regarded as overweight. WAZ: a child who had $\mathrm{WAZ}<-2 \mathrm{SD}$ was categorized as low weightfor-age which implies undernutrition, and those who had WAZ $>2 S D$ were regarded as high weight-for-age, overnutrition.

2.3. Statistical Analysis. After checked for completeness, the collected data were entered into Epi-Data 7 and then exported to SPSS 22 statistical software for further analysis. Descriptive statistics such as mean, percentages, standard deviation, and ranges were done. Comparisons on BMI and school absenteeism were performed with an independent Student's $t$-test, where a $p$ value of less than 0.05 was a measure of statistically significant difference between the two groups. For the identification of factors statistically associated with school absenteeism, binary (bivariable and multivariable) logistics regression was applied, where fitness for the model was checked by the Hosmer-Lemeshow goodness of fit model. A 95\% confidence interval and a $p$ value of less than 0.05 were used as statistically significant levels.

\section{Results}

3.1. Sociodemographic Characteristics. A total of 324 participants aged 6-12 years old were enrolled from 3 selected primary schools. Of these, 162 were from the interventional group whereas 162 were from the control group and the response rate was $100 \%$. Most $(60 \%)$ of the feeding and more than half $(54 \%)$ of the nonfeeding participants were male participants, while most (73\%) of feeding and $78 \%$ of nonfeeding participants reported their father's presence within a family. The majority (92\% and $91 \%)$ of the feeding and nonfeeding participants reported that they lived with their mothers, respectively. Physical measurements of participants depicted that $30 \%$ of feeding participants had a weight measurement of $30-34 \mathrm{KG}$, whereas $33 \%$ of the nonfeeding participants had a weight measurement of 25-29 kg (Table 1).

Most $70 \%$ of the feeding and $77 \%$ of the nonfeeding participants were absent from school due to illness, whereas only $14 \%$ of feeding and $7 \%$ of nonfeeding participants were absent from the school due to working for money and food (Table 2).

3.2. Body Mass Index Measurements. Most of the participants from both feeding and nonfeeding groups were found within the normal range of height-for-age measurements. Concerning BMI, most $98 \%$ of feeding and $90 \%$ of nonfeeding participants were found within the normal range (between 2SD and 2 SD) (Table 3). 
TABLE 1: Sociodemographic characteristics of participants at selected primary schools in Yeka subcity, Addis Ababa, Ethiopia, August 2018 $(n=162$ for each).

\begin{tabular}{|c|c|c|c|c|c|}
\hline \multirow{2}{*}{ Characteristics } & \multirow{2}{*}{ Categories } & \multicolumn{2}{|c|}{ Feeding } & \multicolumn{2}{|c|}{ Nonfeeding } \\
\hline & & Number & $\%$ & Number & $\%$ \\
\hline \multirow{2}{*}{ Sex } & Male & 96 & 60 & 88 & 54 \\
\hline & Female & 66 & 40 & 74 & 46 \\
\hline \multirow{6}{*}{ Age in years } & 7 & 16 & 11 & 12 & 7 \\
\hline & 8 & 14 & 9 & 16 & 10 \\
\hline & 9 & 22 & 14 & 25 & 15 \\
\hline & 10 & 25 & 14 & 23 & 14 \\
\hline & 11 & 37 & 22 & 41 & 25 \\
\hline & 12 & 48 & 30 & 45 & 28 \\
\hline \multirow{7}{*}{ Grade } & Grade 1 & 27 & 17 & 27 & 17 \\
\hline & Grade 2 & 20 & 12 & 22 & 14 \\
\hline & Grade 3 & 24 & 15 & 26 & 16 \\
\hline & Grade 4 & 31 & 19 & 29 & 18 \\
\hline & Grade 5 & 30 & 19 & 24 & 15 \\
\hline & Grade 6 & 21 & 13 & 28 & 17 \\
\hline & Grade 7 & 9 & 5 & 6 & 3 \\
\hline \multirow{2}{*}{ Father presence } & Yes & 119 & 73 & 126 & 78 \\
\hline & No & 43 & 27 & 36 & 22 \\
\hline \multirow{2}{*}{ Mother presence } & Yes & 149 & 92 & 147 & 91 \\
\hline & No & 12 & 8 & 15 & 9 \\
\hline \multirow{3}{*}{ Religion } & Orthodox & 137 & 85 & 148 & 91 \\
\hline & Muslim & 17 & 10 & 8 & 5 \\
\hline & Protestant & 8 & 5 & 6 & 4 \\
\hline \multirow{3}{*}{ Birth order } & First & 63 & 39 & 62 & 38 \\
\hline & Middle & 74 & 46 & 59 & 36 \\
\hline & Last & 25 & 15 & 41 & 26 \\
\hline \multirow{5}{*}{ Weight of participants in $\mathrm{kg}$} & $15-19$ & 10 & 6.17 & 9 & 5.55 \\
\hline & $20-24$ & 42 & 25.92 & 42 & 25.92 \\
\hline & $25-29$ & 36 & 22.22 & 53 & 32.71 \\
\hline & 30-34 & 49 & 30.24 & 47 & 29.01 \\
\hline & 35 and above & 25 & 15.43 & 11 & 6.79 \\
\hline \multirow{5}{*}{ Height in $\mathrm{cm}$} & $<120$ & 21 & 12.96 & 13 & 8.02 \\
\hline & $120-129$ & 32 & 19.75 & 23 & 14.19 \\
\hline & $130-139$ & 49 & 30.24 & 54 & 33.33 \\
\hline & $140-149$ & 44 & 27.16 & 53 & 32.71 \\
\hline & $\geq 150$ & 16 & 9.87 & 19 & 11.72 \\
\hline
\end{tabular}

TABLE 2: School absenteeism and reasons for school absenteeism at selected primary schools in Yeka subcity, Addis Ababa, Ethiopia, August $2018(n=162)$.

\begin{tabular}{|c|c|c|c|c|c|}
\hline \multirow{2}{*}{ Characteristics } & \multirow{2}{*}{ Options } & \multicolumn{2}{|c|}{ Feeding } & \multicolumn{2}{|c|}{ Nonfeeding } \\
\hline & & Number & $\%$ & Number & $\%$ \\
\hline \multirow{2}{*}{ School absenteeism due to illness } & Yes & 113 & 70 & 125 & 77 \\
\hline & No & 49 & 30 & 37 & 23 \\
\hline \multirow{2}{*}{ School absenteeism due to working for money and food } & Yes & 23 & 14 & 11 & 7 \\
\hline & No & 139 & 86 & 151 & 93 \\
\hline \multirow{2}{*}{ School absenteeism due to helping family by work } & Yes & 15 & 9 & 8 & 5 \\
\hline & No & 147 & 91 & 154 & 95 \\
\hline \multirow{2}{*}{ School absenteeism due to hunger } & Yes & 5 & 3 & 2 & 1 \\
\hline & No & 157 & 97 & 160 & 99 \\
\hline \multirow{2}{*}{ School absenteeism due to lack of interest to go to school } & Yes & 6 & 4 & 1 & 1 \\
\hline & No & 156 & 96 & 161 & 99 \\
\hline \multirow{2}{*}{ School absenteeism due to other reasons } & Yes & 10 & 6 & 6 & 4 \\
\hline & No & 152 & 94 & 156 & 96 \\
\hline
\end{tabular}


TABLE 3: Nutritional status of participants at selected primary schools in Yeka subcity, Addis Ababa, Ethiopia, August 2018 ( $n=162$ for each).

\begin{tabular}{|c|c|c|c|c|c|}
\hline \multirow{2}{*}{\multicolumn{2}{|c|}{ Characteristics }} & \multicolumn{4}{|c|}{ Feeding status } \\
\hline & & \multicolumn{2}{|c|}{ Feeding } & \multicolumn{2}{|c|}{ Nonfeeding } \\
\hline & & Number & $\%$ & Number & $\%$ \\
\hline \multirow{3}{*}{ Height for age } & $<-2$ SD & 3 & 1.85 & 1 & 0.617 \\
\hline & -2 to $2 \mathrm{SD}$ & 154 & 95.06 & 154 & 95.06 \\
\hline & $>2 \mathrm{SD}$ & 5 & 3.10 & 7 & 4.32 \\
\hline \multirow{3}{*}{ BMI for age } & $<-2 \mathrm{SD}$ & 0 & 0 & 11 & 6.79 \\
\hline & -2 to $2 \mathrm{SD}$ & 159 & 98.1 & 146 & 90.12 \\
\hline & $>2 \mathrm{SD}$ & 3 & 1.85 & 5 & 3.10 \\
\hline
\end{tabular}

TABLE 4: Nutritional status and school absenteeism of participants at selected primary schools, Addis Ababa, Ethiopia, August 2018 ( $n=162$ for each).

\begin{tabular}{lccc}
\hline Characteristics & & Feeding status & $\begin{array}{c}\text { Feeding } \\
(n=162)\end{array}$ \\
\hline Weight & Mean \pm SD & $28.46 \pm 6.554$ & $27.00 \pm 4.81^{*}$ \\
Height & Mean \pm SD & $1.35 \pm 0.11$ & $1.37 \pm 0.11$ \\
BMI & Mean \pm SD & $15.55 \pm 2.31$ & $14.39 \pm 2.07^{*}$ \\
Number of absent days from school & Mean \pm SD & $2.23 \pm 2.420$ & $3.96 \pm 3.326^{*}$ \\
Last semester average mark & Mean \pm SD & $73.8746 \pm 11.78$ & $73.53 \pm 12.61$ \\
Height for age & $Z$ (mean \pm SD) & $2.01 \pm 0.22$ & $2.03 \pm 0.22$ \\
BMI for age & $Z$ (mean \pm SD) & $2.02 \pm 0.13$ & $1.96 \pm 0.31^{*}$ \\
\hline
\end{tabular}

3.3. Comparison of Feeding versus Nonfeeding (t-Test Findings). There was a statistically significant difference between feeding and nonfeeding groups concerning weight, the number of absent days from school, and BMI for age at $p<0.05$.

Participants of the feeding groups had a higher average weight of $28.46 \pm 6.554$ as compared with the average weight of the nonfeeding groups, $27.00+4.81$ (mean and standard deviation). Participants of feeding groups had a less $(2.23 \pm 2.420$, mean, SD) average school absent days, as compared with the nonfeeding groups $(3.96 \pm 3.326$, mean, SD) at $p<0.05$ (Table 4).

3.4. Factors Associated with School Absenteeism. The odds of having had school absenteeism were 1.796 times higher among feeding participants than nonfeeding participants (AOR: 1.796; 95CI:1.061-3.042, $p<0.05)$. The odds of sustaining absenteeism from the school were 2.257 times higher among feeding participants compared with nonfeeding participants (AOR: 2.257; 95\%CI: 1.291-3.948; $p<0.05$ ). (Table 5).

\section{Discussion}

In this study, participants who enrolled in a school feeding program had a higher average weight than nonfeeding participants and were supported by the study in Vietnam. [22].

Though findings from this study revealed that there was no statistically significant difference on average last semester score between feeding and nonfeeding participants, a study in Argentina [23] stated that school feeding had a positive impact on the improvement of academic performance. A positive impact of the school feeding program on improvements in academic achievement was observed in different countries. Of these, it was observed in Nigeria [24], Kenya [25], Tanzania [26, 27], and Ethiopia [28] that the school feeding program had a positive impact on the academic performance of primary school students.

In this study, participants from the feeding group had lower average school absenteeism as compared to their counter nonfeeding participants. This indicated that, as students go through enrollment to the school feeding program, their tendency of school absenteeism tends to be lower and the same was reported by the studies in Ghana [29], Kenya [30, 31], and the southern part of Ethiopia [32].

Evidence from recommendation suggested that the school feeding program had a positive effect on the reduction of school absenteeism in primary school students. [33] On the contrary, a study in Ghana [34] stated that the school feeding program had no role in the reduction of school absenteeism. This variation might be due to differences in approach of delivery and population type.

In this study, the average BMI for age was significantly higher among feeding participants than nonfeeding participants and was supported by a study in Burkina Faso [35]. In this study, illness was one of the factors statistically associated with school absenteeism. Those students who sustained an illness had more risk of being absent from the school compared with their counterparts. Studies from Nigeria and Ghana also investigated that illness is one of the top factors affecting school absenteeism [36, 37]. 
TABLE 5: Factors associated with school absenteeism at selected primary schools in Addis Ababa, Ethiopia, May 2018.

\begin{tabular}{|c|c|c|c|c|c|}
\hline \multirow{2}{*}{ Characteristics } & \multirow{2}{*}{ Categories } & \multicolumn{2}{|c|}{ School absenteeism } & \multirow{2}{*}{ COR $(95 \% \mathrm{CI})$} & \multirow{2}{*}{ AOR (95\%CI) } \\
\hline & & Absent & Not absent & & \\
\hline \multirow{2}{*}{ Feeding status } & Feeding & 129 & 33 & 1 & 1 \\
\hline & Nonfeeding & 114 & 48 & $1.646(0.989-2.740)$ & $1.796(1.061-3.042)^{*}$ \\
\hline \multirow{2}{*}{ Gender } & Male & 136 & 48 & 1 & 1 \\
\hline & Female & 107 & 33 & $0.874(0.524-1.456)$ & $0.833(0.481-1.442)$ \\
\hline \multirow{3}{*}{ Grade of students } & $1-2$ & 69 & 27 & 1 & 1 \\
\hline & $3-4$ & 86 & 24 & $0.713(0.378-1.345)$ & $0.743(0.387-1.425)$ \\
\hline & $>5$ & 88 & 30 & $0.871(0.474-1.600)$ & $0.757(0.393-1.458)$ \\
\hline \multirow{2}{*}{ Mother presence } & Yes & 223 & 74 & 1 & 1 \\
\hline & No & 20 & 7 & $1.055(0.429-2.594)$ & $0.949(0.373-2.417)$ \\
\hline \multirow{3}{*}{ Birth order } & First & 92 & 33 & 1 & 1 \\
\hline & Middle & 101 & 32 & $0.883(0.503-1.550)$ & $0.936(0.524-1.672)$ \\
\hline & Last & 50 & 16 & $0.892(0.448-1.777)$ & $0.921(0.454-1.869)$ \\
\hline \multirow{2}{*}{ Illness } & Yes & 188 & 50 & 1 & 1 \\
\hline & No & 55 & 31 & $2.119(1.236-3.635)^{*}$ & $2.257(1.291-3.948)^{*}$ \\
\hline
\end{tabular}

${ }^{*} p<0.05 ;{ }^{* *} p<0.001$, statistically significant level.

School feeding programs came to be realized on the ground as part of the strategies to improve nutritional status, reduce absenteeism from school, and enhance academic performance. Studies in different parts of Ethiopia also reported the positive impact of the school feeding program on reducing the school absenteeism of primary school students $[32,38]$. However, in this study, being enrolled in the feeding program had a negative impact on reducing school absenteeism. As a probable justification, this might be due to the fact that students from the feeding group might vary from those who did not enroll in the feeding program and hence they experienced more absenteeism than their counterparts.

\section{Conclusions and Recommendations}

Participants of the feeding groups had higher average weight than non-feeding groups, less average school absent days than their counterparts. The average BMI for age was also higher among the feeding group than those who did not enroll in the feeding program. The expansion of the program was recommended to be undertaken by the concerned stakeholders.

\section{Limitations of the study}

As this study compared nutritional status, academic performance, and absenteeism, it did not identify the factors behind those outcomes. And hence further studies were recommended.
Abbreviations
BMI: Body Mass Index
FAO: $\quad$ Food and Agriculture Organization
HAZ: Height-for-age Z-score
MOE: Minster of Education
$\mathrm{MOH}: \quad$ Minister of Health
MUAC: Midupper arm circumference

SFP: $\quad$ School feeding program

SPSS: $\quad$ Statistical package for social sciences

WAZ: Weight-for-age $Z$-score

WHZ: Weight-for-height $Z$-score.

\section{Data Availability}

All data are already included in the manuscript.

\section{Ethical Approval}

The study protocol was performed in accordance with the ethical principles. Ethical approval was obtained from the ethics review board of Sante Medical College.

\section{Consent}

Consent for publication of the manuscript was not applicable due to the fact that there were no participant's individual data, videos, or images. The data collectors obtained written informed consent from all participants.

\section{Conflicts of Interest}

The authors declare that they have no conflicts of interest.

\section{Authors' Contributions}

Both authors contributed to data analysis, drafting, or revising the article, gave final approval of the version to be published, and agreed to be accountable for all aspects of the work.

\section{Acknowledgments}

The authors thank Sante Medical College for the facilitation of the study. They also thank the study participants for their willingness to take part in the study. 


\section{References}

[1] A. Hawke, Fixing the Broken Promise of Education for All: Findings from the Global Initiative on Out-Of-School Children, ERIC, Montreal, Canada, 2015.

[2] B. Asmare, M. Taddele, S. Berihun, and F. Wagnew, "Nutritional status and correlation with academic performance among primary school children, northwest Ethiopia," $B M C$ Research Notes, vol. 11, no. 1, p. 805, 2018.

[3] M. El Hioui, A. Ahami, Y. Aboussaleh, and S. Rusinek, "The relationship between nutritional status and educational achievements in the rural school children of Morocco," Journal of Neurology and Neurological Disorders, vol. 3, no. 1, p. 101, 2016.

[4] R. Chambers, Challenging the Professions: Frontiers for Rural Development, Intermediate Technology Publications Ltd (ITP), England, UK, 1993.

[5] I. O. Senbanjo, K. A. Oshikoya, O. O. Odusanya, and O. F. Njokanma, "Prevalence of and risk factors for stunting among school children and adolescents in Abeokuta, Southwest Nigeria," Journal of Health, Population, and Nutrition, vol. 29, no. 4, p. 364, 2011.

[6] F. Opoola, S. Adebisi, and A. Ibegbu, "The Study of nutritional status and academic performance of primary school children in zaria, Kaduna state, Nigeria," Annals of Bioanthropology, vol. 4, no. 2, p. 96, 2016.

[7] F. Abebe, A. Geleto, L. Sena, and C. Hailu, "Predictors of academic performance with due focus on undernutrition among students attending primary schools of Hawa Gelan district, Southwest Ethiopia: a school based cross sectional study," BMC Nutrition, vol. 3, no. 1, p. 30, 2017.

[8] African Union Commission, The Cost of Hunger in Africa: Social and Economic Impact of Child Undernutrition, African Union Commission, Addis Ababa, Ethiopia, 2012.

[9] T. Benson, S. Bellete, C. Demese et al., An Assessment of the Causes of Malnutrition in Ethiopia: A Contribution to the Formulation of a National Nutrition Strategy for Ethiopia, International Food Policy Research Institute, Washington, DC, USA, 2005.

[10] Z. Getaneh, M. Melku, M. Geta, T. Melak, and M. T. Hunegnaw, "Prevalence and determinants of stunting and wasting among public primary school children in Gondar town, northwest, Ethiopia," BMC Pediatrics, vol. 19, no. 1, p. 207, 2019.

[11] E. Z. Tariku, G. A. Abebe, Z. A. Melketsedik, and B. T. Gutema, "Prevalence and factors associated with stunting and thinness among school-age children in arba minch health and demographic surveillance site, southern Ethiopia," PloS One, vol. 13, no. 11, 2018.

[12] H. Mekonnen, T. Tadesse, and T. Kisi, "Malnutrition and its correlates among rural primary school children of Fogera District, Northwest Ethiopia," Journal of Nutritional Disorders and Therapy S, vol. 12, pp. 2161-0509, 2013.

[13] M. Sarma, D. Wijesinghe, and T. Sivananthawerl, "The effects of nutritional status on educational performance of primary school children in the plantation sector in Nuwara Eliya Educational Zone," Tropical Agricultural Research, vol. 24, no. 3, pp. 14-203, 2013.

[14] D. Shaw, The UN World Food Programme and the Development of Food Aid, Springer, Heidelberg, Germany, 2001.

[15] L. H. Jomaa, E. McDonnell, and C. Probart, "School feeding programs in developing countries: impacts on children's health and educational outcomes," Nutrition Reviews, vol. 69, no. 2, pp. 83-98, 2011.
[16] H. Joulaei, E. Nwagwu, A. Nasihatkon et al., "To assess the effects of nutritional intervention based on advocacy approach on malnutrition status among school-aged children in Shiraz," Journal of Research in Medical Sciences: The Official Journal of Isfahan University of Medical Sciences, vol. 18, no. 9, p. 739, 2013.

[17] A. Buttenheim, H. Alderman, and J. Friedman, Impact Evaluation of School Feeding Programs in Lao PDR, The World Bank, Washington, DC, USA, 2011.

[18] C. A. Kearney and A. Bensaheb, "School absenteeism and school refusal behavior: a review and suggestions for school-based health professionals," Journal of School Health, vol. 76, no. 1, pp. 3-7, 2006.

[19] D. A. Bundy, L. J. Drake, and C. Burbano, "School food, politics and child health," Public Health Nutrition, vol. 16, no. 6, pp. 1012-1019, 2013.

[20] A. Singh, A. Park, and S. Dercon, "School meals as a safety net: an evaluation of the midday meal scheme in India," Economic Development and Cultural Change, vol. 62, no. 2, pp. 275-306, 2014.

[21] F. Afridi, "The impact of school meals on school participation: evidence from rural India," Journal of Development Studies, vol. 47, no. 11, pp. 1636-1656, 2011.

[22] A. Hall, T. T. M. Hanh, K. Farley, T. P. N. Quynh, and F. Valdivia, "An evaluation of the impact of a school nutrition programme in Vietnam," Public Health Nutrition, vol. 10, no. 8, pp. 819-826, 2007.

[23] C. Adrogue and M. E. Orlicki, "Do in-school feeding programs have an impact on academic performance and dropouts? the case of public schools in Argentina," Education Policy Analysis Archives, vol. 21, p. 50, 2013.

[24] D. T. Adekunle and O. O. Christiana, "The effects of school feeding programme on enrolment and performance of public elementary school pupils in osun state, Nigeria," World Journal of Education, vol. 6, no. 3, pp. 39-47, 2016.

[25] B. C. Chepkwony, L. J. Kosgei, and B. M. Kariuki, "School feeding program and its impact on academic achievement in ECDE in Roret division, Bureti district in Kenya," Journal of Emerging Trends in Educational Research and Policy Studies, vol. 4, no. 3, pp. 407-412, 2013.

[26] J. K. Ramadhani, An Assessment of the Effects of School Feeding Programme on the School Enrolment, Attendance and Academic Performance in Primary Schools in Singida District, The Open University of Tanzania, Dar es Salaam, Tanzania, 2014.

[27] S. N. Maijo, "Impact of school feeding programme on learners' academic performance in mlunduzi ward, Tanzania," International Journal of Educational Studies, vol. 5, no. 3, pp. 125-130, 2018.

[28] A. Yohannes, The Effect of School Feeding Program on the School Performance of Primary Public School Children in Arada Sub City, Addis Ababa, Addis Ababa University, Addis Ababa, Ethiopia, 2017.

[29] F. Dayour, "Effect of the national school feeding programme on pupils' enrolment, attendance and retention: a case study of nyoglo of the savelugu-nantong municipality, Ghana," Canadian Journal of Behavioural Science, vol. 5, pp. 341-353, 2015.

[30] K. Rael, Influence of School Feeding Programmes on Pupils'participation in Primary School Education in Samburu East Constituency, University Of Nairobi, Samburu County, Kenya, 2017.

[31] Km Chege, "Influence of school feeding programme on pupils'participation in primary schools in conflict areas: the 
case of Isiolo central district, Kenya," Unpublished Med Thesis, University of Nairobi, Nairobi, Kenya, 2013.

[32] M. Zenebe, S. Gebremedhin, C. J. Henry, and N. Regassa, "School feeding program has resulted in improved dietary diversity, nutritional status and class attendance of school children," Italian Journal of Pediatrics, vol. 44, no. 1, p. 16, 2018.

[33] E. A. Kristjansson, A. Gelli, V. Welch et al., "Costs, and cost-outcome of school feeding programmes and feeding programmes for young children. evidence and recommendations," International Journal of Educational Development, vol. 48, pp. 79-83, 2016.

[34] A. Abotsi, "Expectations of school feeding programme: impact on school enrolment, attendance and academic performance in elementary Ghanaian schools," British Journal of Education, Society \& Behavioural Science, vol. 3, no. 1, pp. 76-92, 2013.

[35] D. A. Bundy, N. de Silva, S. Horton, D. Jamison, and G. C. Patton, Optimizing Education Outcomes: High-Return Investments in School Health for Increased Participation and Learning, World Bank, Washington, DC, USA, 2018.

[36] M. N. Amalu and K. B. Abang, "School absenteeism among primary school pupils in cross river state: psychological implication for national development," Global Journal of Educational Research, vol. 15, no. 1, pp. 49-56, 2016.

[37] K. Etsey, "Causes of low academic performance of primary school pupils in the shama sub-metro of shama ahanta east metropolitan assembly (SAEMA) in Ghana," in Proceedings of the Regional Conference on Education in West Africa, Accra, Ghana, August 2005.

[38] R. Gallenbacher, Impact of School Feeding on Primary School Education in Ethiopia, University of Vienna, Vienna, Austria, 2018. 